\title{
Recovery from Cucurbit leaf crumple virus (Family Geminiviridae, Genus Begomovirus) Infection Is an Adaptive Antiviral Response Associated with Changes in Viral Small RNAs
}

\author{
C. Hagen, M. R. Rojas, T. Kon, and R. L. Gilbertson
}

Department of Plant Pathology, University of California-Davis, 95616.

Accepted for publication 10 May 2008.

\begin{abstract}
Hagen, C., Rojas, M. R., Kon, T., and Gilbertson, R. L. 2008. Recovery from Cucurbit leaf crumple virus (family Geminiviridae, genus Begomovirus) infection is an adaptive antiviral response associated with changes in viral small RNAs. Phytopathology 98:1029-1037.

A strong recovery response occurs in cantaloupe (Cucumis melo) and watermelon (Citrullus lanatus) infected with the bipartite begomovirus Cucurbit leaf crumple virus (CuLCrV). This response is characterized by initially severe symptoms, which gradually become attenuated (almost symptomless). An inverse relationship was detected between viral DNA levels and recovery, indicating that recovered tissues had reduced viral titers. Recovered tissues also were resistant to reinfection with $\mathrm{CuLCrV}$; i.e., recovered leaves reinoculated with the virus did not develop symptoms or have an increased level of viral DNA. In contrast, infection of $\mathrm{CuLCrV}$-recovered leaves with the RNA virus, Cucumber mosaic virus

(CMV), disrupted recovery, resulting in the development of severe disease symptoms (more severe than those induced by $\mathrm{CMV}$ or $\mathrm{CuLCrV}$ alone) and increased CuLCrV DNA levels. Small RNAs with homology to CuLCrV DNA were detected in recovered and nonrecovered tissues; as well as in phloem exudates from infected, but not uninfected plants. Levels of these small RNAs were positively correlated with viral titer; thus, recovered tissues had lower levels than symptomatic tissues. In addition, viral DNA from a host that undergoes strong recovery (watermelon) was more highly methylated compared with that from a host that undergoes limited recovery (zucchini). Furthermore, inoculation of CuLCrV-infected zucchini with a construct expressing an inverted repeat of the CuLCrV common region enhanced recovery and reduced viral symptoms and viral DNA levels in newly emerged leaves. Taken together, these results suggest that recovery from $\mathrm{CuLCrV}$ infection is an adaptive antiviral defense mechanism, most likely mediated by gene silencing.
\end{abstract}

Cucurbit leaf crumple virus (CuLCrV; family Geminiviridae, genus Begomovirus) is a whitefly-transmitted cucurbit-infecting virus that has recently emerged in the southwestern United States. The virus was first identified in the fall of 1998 in the Imperial Valley of California (19), and now has been reported from the Coachella Valley of California, New Mexico, and Arizona as well as northern Mexico $(8,20)$. The host range of $\mathrm{CuLCrV}$ consists primarily of species in the family Cucurbitaceae, e.g., in the genera Cucurbita and Cucumis, but also includes certain common bean (Phaseolus vulgaris) cultivars $(8,20,25)$.

Symptoms of CuLCrV infection in susceptible cucurbits include stunted and distorted growth; and crumpling, curling, yellow spotting, and chlorosis of leaves. Disease symptoms can be severe, especially in Cucurbita spp. (e.g., various types of squash), and may result in yield losses (20). In contrast, symptoms of $\mathrm{CuLCrV}$ in susceptible Cucumis spp. (e.g., cantaloupe and watermelon) are initially severe, but then become highly attenuated and remain so for the life of the plant. In the field, the practical effect of this 'recovery phenotype' is that $\mathrm{CuLCrV}$ causes relatively little yield loss in cucurbits such as cantaloupe and watermelon (20).

Recovery has previously been observed in other begomovirushost combinations; for example, in cassava (Manihot esculenta Crantz) infected with African cassava mosaic virus (ACMV) (13), and in pepper plants infected with Pepper golden mosaic virus (PepGMV) (11). Recovery from infection by another type of DNA virus, Cauliflower mosaic virus, has been associated with

Corresponding author: R. L. Gilbertson; E-mail address: rlgilbertson@ucdavis.edu

doi:10.1094/PHYTO-98-9-1029

(c) 2008 The American Phytopathological Society posttranscriptional gene silencing (PTGS) (14). PTGS is a type of host defense response to parasitic or foreign nucleic acids, such as viruses, and occurs in higher plants and animals. When viral infection is targeted, this defense response is referred to as virusinduced gene silencing (VIGS), and can lead to a reduction in viral titer and disease symptoms $(13,14,34)$. One of the hallmarks of PTGS, in the plant, is the appearance of small (21 to $25 \mathrm{nt}$ ) RNAs (siRNAs) (21). In VIGS, these siRNAs represent portions of the viral RNA that have been cleaved by silencing machinery $(10,23)$. These siRNAs then act to direct the RNA induced silencing complex (RISC) (22) to further degrade homologous viral RNAs. Although all the routes by which an RNA can be recognized and trigger PTGS are not known, it is clear that dsRNA (a common viral replication intermediate) is a potent target for silencing (46). However, as geminiviruses have a single-stranded DNA genome and do not replicate via dsRNAs, it is probable that either messenger RNA transcript levels or secondary structure trigger geminivirus silencing. Interestingly, it is now clear that higher plants and animals also utilize gene silencing for gene regulation; this is especially common in development $(4,32)$. Thus, some classes of small RNAs (e.g., microRNAs) are important developmental signals $(40,48)$.

In addition to the activation of PTGS, there is evidence that transcriptional gene silencing (TGS) is also active against geminiviruses (35). TGS is associated with DNA methylation of a targeted sequence, usually a promoter, resulting in highly attenuated or silenced gene transcription for the remainder of the life of the plant (3). Unlike PTGS, TGS can also be transmitted through the germline (33). Geminivirus promoters are negatively influenced by DNA methylation (16), and artificially methylated geminivirus DNA is poorly replicated in plant cells (7). Thus, there is strong selection pressure to maintain unmethylated viral DNA in infected cells (16). 
In this study, we test the hypothesis that the $\mathrm{CuLCrV}$ recovery phenotype is a host defense response, associated with gene silencing. We demonstrate that the recovery phenotype is (i) a defense response associated with $\mathrm{CuLCrV}$ homologous small RNA, (ii) repressed by co-infection with an RNA virus, $\mathrm{Cu}$ cumber mosaic virus (CMV), that expresses a strong suppressor of silencing, and (iii) associated with methylation of geminiviral DNA. Finally, the recovery phenotype was triggered by inoculation with an inverted repeat construct that produces dsRNA corresponding to the common region (CR) of the $\mathrm{CuLCrV}$ genome.

\section{MATERIALS AND METHODS}

Particle bombardment inoculation of CuLCrV. Generation of multimeric full-length infectious clones of CuLCrV DNA-A (pCuLCrVA1.5) and DNA-B (pCuLCrVB1.5) has been previously described (20). Particle bombardment inoculation was performed as described in Paplomatas et al. (31). Briefly, $1 \mu \mathrm{g}$ each of pCuLCrVA1.5 and pCuLCrVB1.5 were mixed, coated onto gold particles, and bombarded (900 psi) into cantaloupe (Cucumis melo L. cv. Laredo), watermelon (Citrullus lanatus Thunb. cv. Charleston grey), zucchini (Cucurbita pepo L. cv. Elite), and pumpkin (Cucurbita maxima Duchesne cv. Big Max) seedlings at the one to two true leaf stage (10 days post-germination [dpg]) with a PDS-1000 microparticle delivery system (DuPont, Wilmington, DE). Seedlings were maintained in a controlled environment growth chamber (light intensity $300 \mu$ Einsteins, temperature $30^{\circ} \mathrm{C}$ day $/ 25^{\circ} \mathrm{C}$ night, $16 \mathrm{~h}$ day length and relative humidity of $\approx 60 \%$ ) or a greenhouse maintained between 25 and $28^{\circ} \mathrm{C}$. Symptom assessment was made $10,20,30$, or 40 days post-bombardment (dpb), and infection in selected plants was confirmed by polymerase chain reaction (PCR) analysis with $\mathrm{CuLCrV}$-specific primers (20). Unless otherwise noted, all experiments in this study were repeated at least three times with three to four plants/treatment/experiment.

Agroinoculation of CuLCrV. The generation and testing of a $\mathrm{CuLCrV}$ agroinoculation system in plants has been previously described (20). Briefly, Agrobacterium strains carrying binary plasmids with multimeric clones of CuLCrV DNA-A (pCuLCrVA1.5agro) and DNA-B (pCuLCrVB1.5agro) were grown in liquid media supplemented with tetracycline $(10 \mathrm{mg} / \mathrm{liter}$; tetracycline hydrochloride; Sigma, St. Louis, MO) to an optical density of $\approx 1$ at $600 \mathrm{~nm}$. These cultures were mixed and cucurbit seedlings at the two true leaf stage were agroinoculated at the first internode by needle puncture inoculation with a $10 \mathrm{cc}$ syringe and 27-gauge sterile needle. Inoculated plants were maintained in a controlled environment chamber or under controlled greenhouse conditions as previously described. Symptom assessment was made 10, 20, and 30 days postinoculation (dpi), and infection in selected plants was confirmed by PCR analysis with $\mathrm{CuLCrV}$ specific primers.

Assessment of viral DNA level with DNA gel blot hybridization analysis. DNA gel blot hybridization analyses were conducted as previously described (27). Briefly, DNA was isolated from newly emerged leaves with the Dellaporta method (15), extracted with phenol/chloroform and concentrated by ethanol precipitation. Unless otherwise noted, $3 \mu \mathrm{g}$ of undigested total genomic DNA per plant was fractionated in $1 \%$ agarose gels in TAE buffer (36). Equal loading of the agarose gels and integrity of the DNA was confirmed by ethidium bromide staining and visualization under UV light. DNA was transferred onto Hybond$\mathrm{N}$ nylon membranes (Amersham Biosciences, Piscataway, NJ). Radiolabeling of plasmid DNA (pCuLCrVA1.5 and pCuLCrVB1.5) with deoxycytidine 5 -triphosphate $\left[\alpha-{ }^{32} \mathrm{P}\right]$ was performed with a nick translation system (Invitrogen, Carlsbad, CA) according to the manufacturer's instructions. Blots were hybridized with equal quantities of ${ }^{32} \mathrm{P}$-labeled pCuLCrVA1.5 and pCuLCrVB1.5 (CuLCrV DNA-A and DNA-B probe). Blotting and hybridization was carried out as previously described (26), and hybridization signals were visualized by autoradiography.

Viral DNA levels in nonrecovered (symptomatic) and recovered tissues. Watermelon (cv. Charleston grey), cantaloupe (cv. Laredo), and zucchini (cv. Elite) seedlings were inoculated with CuLCrV DNA-A and DNA-B by particle bombardment, and maintained in a growth chamber as previously described. Newly emerged leaves were collected from CuLCrV-infected plants at 10 (leaves 3 to 5) and $20 \mathrm{dpb}$ (leaves 6 to 9), and DNA was extracted as described previously. To determine CuLCrV DNA levels, DNA gel blot hybridization analysis of total genomic DNA from leaf tissues of non-recovered $(3 \mu \mathrm{g})$ or recovered $(6 \mu \mathrm{g})$ plants was performed with the CuLCrV DNA-A and DNA-B probe.

Reinoculation of recovered watermelon plants with $\mathrm{CuLCrV}$. Watermelon (cv. Charleston grey) seedlings were germinated and divided into three groups: 'early', inoculated with $\mathrm{CuLCrV}$ at $10 \mathrm{dpg}$; 'late', inoculated at $30 \mathrm{dpg}$; and 'early and late', inoculated at 10 and $30 \mathrm{dpg}$. Seedlings at $10 \mathrm{dpg}$ ( 1 to 2 true leaf stage) were inoculated with $\mathrm{CuLCrV}$ by particle bombardment, whereas plants at $30 \mathrm{dpg}$ (6 to 9 true leaf stage) were agroinoculated with $\mathrm{CuLCrV}$ by needle puncture inoculation just below the shoot apex. Plants in the 'early and late' group were confirmed to be infected with $\mathrm{CuLCrV}$ following particle bombardment inoculation (based upon symptom development and PCR analysis) before being inoculated at $30 \mathrm{dpg}$. Plants were assessed for symptom development and newly emerged leaves were collected for DNA extraction at 10, 20, 30, 40, and $50 \mathrm{dpg}$. DNA was extracted from leaf tissue as described, and CuLCrV DNA levels were determined by DNA gel blot hybridization analysis (6 $\mu \mathrm{g}$ of DNA/ plant) with the CuLCrV DNA-A and DNA-B probe.

Infection of CuLCrV-recovered plants with CMV. Cantaloupe (cv. Laredo) seedlings (10 dpg) were inoculated with CuLCrV DNA-A and DNA-B by particle bombardment, maintained in a growth chamber, and monitored for infection based upon symptom development and PCR analysis. At $30 \mathrm{dpg}(20 \mathrm{dpb})$, CuLCrV-infected plants (6 to 9 true leaf stage) were inoculated with CMV (family Bromoviridae, genus Cucumovirus) strain 113b (39) by sap inoculation. Sap was prepared by grinding young CMV-infected leaves from pumpkin plants (cv. Small sugar) in ice-cold $0.1 \mathrm{M}$ of potassium phosphate buffer ( $\mathrm{pH} 7.8$ ) with a mortar and pestle, and then rubbed onto celite-dusted young leaves with a pestle. Plants were maintained in a greenhouse as described. Controls consisted of (i) cantaloupe seedlings infected with $\mathrm{CuLCrV}$ by particle bombardment and rub-inoculated with buffer alone at $20 \mathrm{dpb}$ (mock), (ii) equivalent cantaloupe plants sap-inoculated with CMV alone (30 dpg), and (iii) uninfected cantaloupe plants. Plants were assessed for symptom development and newly emerged leaves were collected for DNA extraction at $10,20,30,40$, and $50 \mathrm{dpg}$. DNA was extracted from leaf tissue as described and CuLCrV DNA levels were determined by DNA gel blot hybridization analysis (6 $\mu \mathrm{g}$ of DNA/plant) with the $\mathrm{CuLCrV}$ DNA-A and DNA-B probe.

Small RNA analysis. Watermelon (cv. Charleston grey) seedlings were inoculated with CuLCrV DNA-A and DNA-B by particle bombardment and maintained in a growth chamber as described. Newly emerged leaf tissue was sampled from infected plants at 10 (leaves 3 to 5) and $20 \mathrm{dpb}$ (leaves 6 to 9), and RNA was extracted with TRIzol (Invitrogen) according to the manufacturer's instructions. RNA concentration was determined with a spectrophotometer, and $20 \mu \mathrm{g}$ of RNA/sample was fractionated in $15 \%$ polyacrylamide-7 M urea denaturing gels (Ambion, Austin, TX). Radioactively-labeled RNA size markers (Decade markers, Ambion, Austin, TX) were used to estimate size of small RNAs. Equal loading of the gels and integrity of the RNA was determined by visualization of ethidium-bromide stained gels. The RNA was transferred to a Genescreen Plus membrane (Perkin Elmer, Wellesley, MA) with a semi-dry transfer apparatus (BioRad, Hercules, CA). PerfectHyb Plus buffer (Sigma-Aldrich, St. 
Louis, MO) was used for pre-hybridization and hybridization. Hybridization was performed with an $\propto-{ }^{32} \mathrm{P}$-labeled $\mathrm{CuLCrV}$ DNA-A probe (pCuLCrVA1.5) at $35^{\circ} \mathrm{C}$ for $14 \mathrm{~h}$. The probe was labeled by random priming with the Megaprime DNA labeling system (Amersham Biosciences) according to the manufacturer's instructions. Washes were performed at $45^{\circ} \mathrm{C}$, first with $1 \times \mathrm{SSC}$ ( $1 \times \mathrm{SSC}$ is $0.15 \mathrm{M} \mathrm{NaCl}$ plus $0.015 \mathrm{M}$ sodium citrate) and $0.1 \%$ sodium dodecyl sulfate (SDS) for $40 \mathrm{~min}$; and then with $0.5 \times$ SSC and $0.1 \%$ SDS for $120 \mathrm{~min}$. Hybridization signals were visualized by autoradiography.

Small RNA isolation from Cucurbita maxima phloem exudate. Pumpkin plants (cv. Big Max) at the two true leaf stage were inoculated with CuLCrV DNA-A and DNA-B by particle bombardment and maintained in a growth chamber as described. At $10 \mathrm{dpb}$, infected plants were identified based on symptom development and PCR analysis. Infected and gold-bombarded (mock) plants were then maintained under identical environmental conditions until $30 \mathrm{dpb}$, whereupon phloem exudate was collected, and RNA extracted with TRIzol (Invitrogen) and processed as described in Yoo et al. (47). The presence and concentration of RNA in these extracts was determined by polyacrylamide gel electrophoresis and comparison with RNA markers of known concentration. RNA gel blot analysis $(20 \mu \mathrm{g}$ of RNA/ sample) was performed as previously described with a $\mathrm{CuLCrV}$ DNA-A and DNA-B probe labeled by random priming with $\mathrm{dCT} \propto-{ }_{-32} \mathrm{P}$ with the Random Primers DNA Labeling System (Invitrogen).

Methylation analysis of the CuLCrV genome before and after recovery. To determine if the $\mathrm{CuLCrV}$ genome was methylated, total genomic DNA was extracted from nonrecovered and recovered tissues of $\mathrm{CuLCrV}$-infected plants, and restriction enzyme digestion analysis was performed with methylationsensitive (HpaII) and methylation-insensitive (MspI) restriction enzymes. Seedlings of watermelon (cv. Charleston grey), a host that undergoes strong recovery, and zucchini (cv. Elite) a host that undergoes limited recovery, were agroinoculated with $\mathrm{CuLCrV}$ DNA-A and DNA-B. At 10, 20, and 30 dpi, leaf tissue samples were taken from $\mathrm{CuLCrV}$-infected and uninfected control plants. Total genomic DNA was extracted from $0.1 \mathrm{~g}$ of leaf tissue from each plant, and DNA samples were quantified with a spectrophotometer. To confirm that inhibitors were not present in these extracts, plasmid DNA with CuLCrV DNA-A (pCuLCrVA1.5) was added to DNA extracts prepared from watermelon and zucchini leaves at 20 dpi and subjected to digestion with HpaII and MspI. An additional control was plasmid DNA digested alone.

For each sample, $10 \mu \mathrm{g}$ of total genomic DNA were digested for $16 \mathrm{~h}$ with HpaII or MspI according to the manufacturer's instructions (New England Biolabs, Beverly, MA). Mung bean nuclease (10 units/10 $\mu \mathrm{g}$ of total genomic DNA; New England Biolabs) was added following restriction enzyme digestion to degrade single-stranded DNA. All digestion reactions were extracted with phenol-chloroform and DNA recovered by ethanol precipitation. All of the DNA recovered after from the digestion, as well as undigested DNA of each sample $(3 \mu \mathrm{g})$, were analyzed by agarose gel electrophoresis in $1.5 \%$ agarose gels in TAE buffer. DNA gel blot hybridization analysis was performed as previously described with a ${ }^{32} \mathrm{P}$-labeled pCuLCrVA1.5 probe.

Assessment of a CuLCrV common-region inverted repeat construct for inducing recovery. To generate a $\mathrm{CuLCrV} \mathrm{CR}$ inverted repeat construct, pHANNIBAL (24) was used. Four primers were designed, each having a different restriction site (XbaI, XhoI, ClaI, or KpnI) engineered into their $5^{\prime}$ ends. The names (with the restriction site indicated) and sequences of the primers are as follows: XbaI2323: 5'-ACCTTCTAGACGTCGGAATGTTCCTCTC-3'; XhoI2323: 5'-ACCTCTCGAGCGTCGGAATGTTCCTCTC-3'; ClaI2632: 5'-TGGTATCGATAATATTATTGCGGATGGC-3'; and KpnI2632: 5'-TGGTGGTACCAATATTATTGCGGATGGC-3'. Primer pairs with different 5' restriction enzyme combinations (e.g., $\mathrm{XbaI}$ and $\mathrm{ClaI}$, and $\mathrm{XhoI}$ and $K p n I$ ) were used to direct the amplification of the target $\approx 300$ bp region of the CuLCrV DNA-A genome (from near the $5^{\prime}$ end of the AC1 gene [nt 2322] to the $3^{\prime}$ end of the CR [nt 2632]). The resulting fragments were digested with the appropriate restriction enzyme combinations and inserted in either a sense or antisense orientation into pHANNIBAL. This cloning was accomplished in a two-stage ligation to generate pHANNIBAL:Cu. The integrity of the construct was confirmed by sequence analysis. A DNA fragment containing the inverted repeat was excised from pHANNIBAL:Cu with NotI, which releases an $\approx 3.5 \mathrm{~kb}$ insert (including the $35 \mathrm{~S}$ promoter, the $\mathrm{CuLCrV}$ inverted repeat separated by an intron, and the OCS terminator). This fragment was gel purified and cloned into the binary vector pART27 (17) to generate pHANNIBAL:Cu-agro. pHANNIBAL:Cu-agro was initially transformed into $E$. coli (strain $\mathrm{DH} 5 \propto$ ), and plasmid DNA was purified. This plasmid DNA was then transformed into A. tumefaciens (strain C58) by electroporation. Transformants were identified by growth on solid media supplemented with spectinomycin (25 mg/liter; Sigma). The presence of pHANNIBAL:Cu-agro in Agrobacterium strain C58 was verified by PCR with various combinations of the XbaI2323, XhoI2323, ClaI2632, and KpnI2632 primers.

Treatment of CuLCrV-infected $C$. pepo with pHANNIBAL: Cu-agro. Zucchini (cv. Elite) plants were infected with $\mathrm{CuLCrV}$ DNA-A and DNA-B by particle bombardment. At $10 \mathrm{dpb}$, infected (symptomatic) plants were agroinoculated with pHANNIBAL:Cu-agro by needle puncture inoculation. Inoculated plants were maintained in a controlled environment growth chamber. Agroinoculation with pHANNIBAL:Cu-agro was performed two more times, at 17 and $24 \mathrm{dpb}$. Controls were equivalent $\mathrm{CuLCrV}$-infected zucchini plants agroinoculated with a strain harboring an 'empty' pHANNIBAL vector (i.e., not containing the inverted repeat insert). These control plants were maintained and sampled in parallel. Newly emerging leaves were visually assessed for disease symptoms and sampled at 10, 17, and $24 \mathrm{dpb}$. After the tissue samples were collected from plants at the $24 \mathrm{dpb}$ time point, DNA was extracted and quantified by spectrophotometry. Viral DNA levels were determined by DNA gel blot analysis as previously described.

\section{RESULTS}

Characterization of recovery from $\mathrm{CuLCrV}$ infection in cucurbits: viral DNA levels in recovered versus nonrecovered tissues. By $10 \mathrm{dpb}$ with the cloned infectious CuLCrV DNA-A and DNA-B components, severe symptoms of leaf crumple, curl, and chlorosis had developed in newly emerged leaves $(\approx 3$ to 5 true leaf stage) of CuLCrV-infected cantaloupe, watermelon, and zucchini plants (Fig. 1A, C, and D). By 20 dpi ( $\approx 6$ to 9 true leaf stage), these symptoms had become considerably attenuated in newly emerging leaves of watermelon and cantaloupe plants (Fig. $1 \mathrm{~B}$ and $\mathrm{C}$ ), but not in equivalent-aged leaves of zucchini (Fig. 1E). Symptoms in $\mathrm{CuLCrV}$-infected cantaloupe and watermelon plants remained attenuated and, by the end of the experiment (50 dpb), leaves were essentially symptomless. This viral recovery phenotype was consistently observed in cantaloupe and watermelon over numerous independent experiments, and is consistent with observation of recovery in these hosts in the field (20). In contrast, the symptoms in zucchini and pumpkin (cv. Big Max) plants remained severe for the duration of the experiment (Fig. 1F), although some attenuation of symptoms was observed in newly emerged leaves of these hosts by $50 \mathrm{dpg}$.

Levels of $\mathrm{CuLCrV}$ viral DNA in leaves of infected plants was positively correlated with symptom severity (Fig. 2). Thus, at $10 \mathrm{dpb}$, when plants of all species showed severe symptoms, viral DNA levels were high, particularly in watermelon and zucchini (Fig. 2). However, by $20 \mathrm{dpb}$, when cantaloupe and watermelon 
plants started to undergo recovery, viral DNA levels were considerably reduced compared with those detected in symptomatic (nonrecovered) leaves (Fig. 2). In contrast, at $20 \mathrm{dpb}$, symptoms were still evident in zucchini leaves and viral DNA levels remained high in these nonrecovered leaves. These results were observed in three independent experiments, and indicate that the recovery phenotype is associated with a reduction in viral titer.

Reinoculation of recovered plants with CuLCrV. To determine if the recovery phenotype could be reversed (i.e., back to the symptomatic phenotype), watermelon (cv. Charleston grey) plants, infected with CuLCrV by particle bombardment and undergoing recovery $(20 \mathrm{dpb} ; 30 \mathrm{dpg})$, were reinoculated with $\mathrm{CuLCrV}$ by agroinoculation. Following reinoculation, newly emerging leaves did not display symptoms of CuLCrV infection by $10 \mathrm{dpi}$, or over the duration of the experiment $(50 \mathrm{dpg}, 20$ days post-reinoculation). Indeed, symptoms in these reinoculated plants were
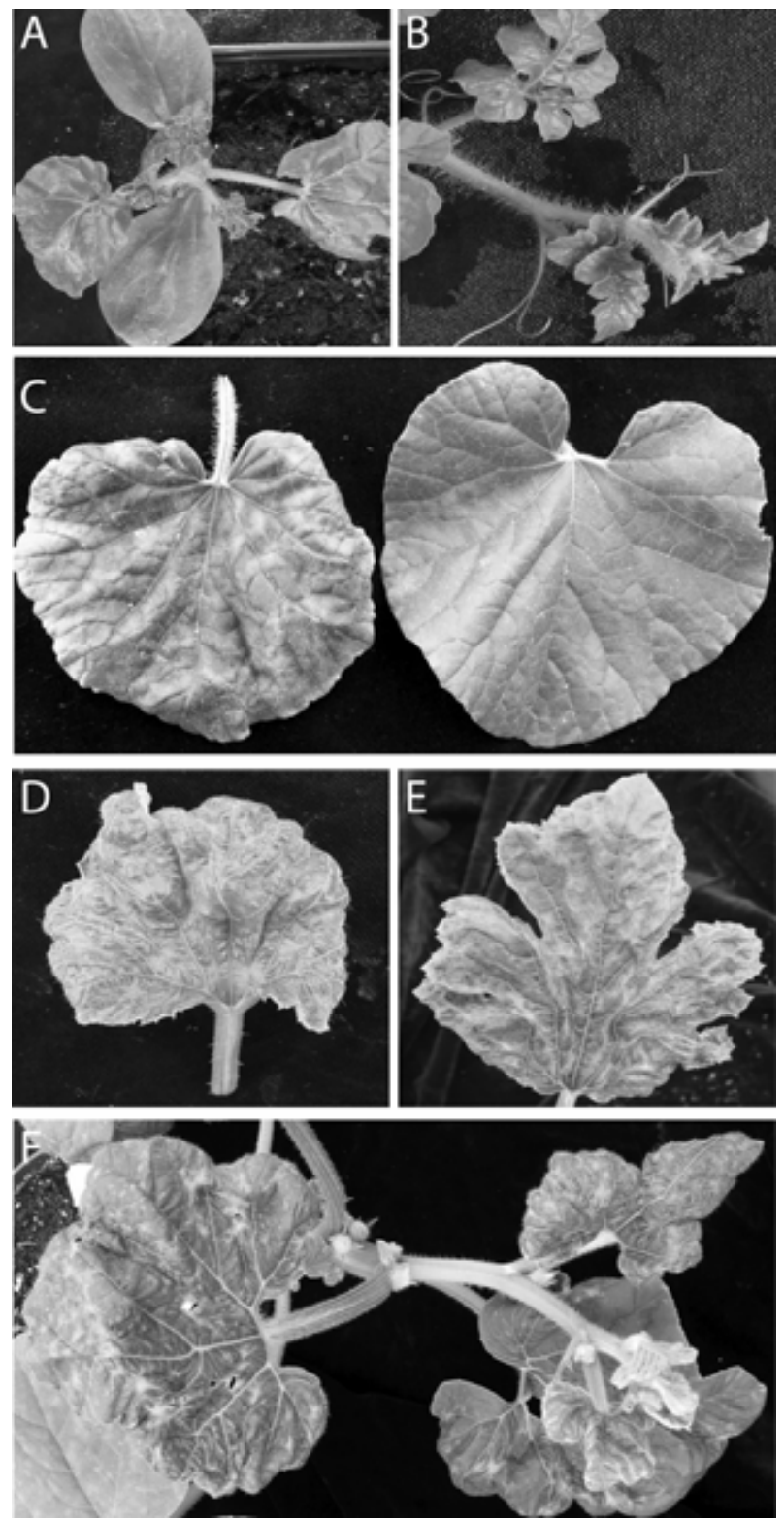

Fig. 1. Disease symptoms observed in cucurbits 10 and 20 days post-particle bombardment $(\mathrm{dpb})$ inoculation with the cloned multimeric DNA-A and DNA-B components of Cucurbit leaf crumple virus (CuLCrV). A, Watermelon (cv. Charleston grey) seedlings at $10 \mathrm{dpb}$ and $\mathbf{B}, 20 \mathrm{dpb}$; C, cantaloupe (cv. Laredo) leaves showing typical symptoms of CuLCrV infection at $10 \mathrm{dpb}$ (nonrecovered, left) and recovery from CuLCrV infection at $20 \mathrm{dpb}$ (recovered, right); D and E, Zucchini leaves (cv. Elite) showing typical symptoms at 10 and $20 \mathrm{dpb}$, respectively; and F, pumpkin (cv. Big Max), $20 \mathrm{dpb}$. indistinguishable from those in equivalent recovered plants that were not reinoculated. In contrast, equivalent uninfected plants, agroinoculated with $\mathrm{CuLCrV}$ at $30 \mathrm{dpg}$, developed typical severe CuLCrV symptoms (leaf crumpling and curling) by 10 dpi (Table 1). Levels of viral DNA were positively correlated with symptom development (Fig. 3), with highest levels detected in symptomatic leaves, and much lower levels detected in recovered leaves, irrespective of reinoculation with $\mathrm{CuLCrV}$ (Table 1).

Infection of CuLCrV-recovered plants with CMV. To further attempt to reverse the recovery phenotype, cantaloupe (cv. Laredo) plants infected with $\mathrm{CuLCrV}$ via particle bombardment inoculation and undergoing recovery ( $20 \mathrm{dpb} ; 30 \mathrm{dpg})$ were sapinoculated with CMV. Control plants sap-inoculated with CMV at the equivalent stage of development developed crumpling, yellow spots, and chlorosis in newly emerging leaves by $10 \mathrm{dpi}$. When leaves of $\mathrm{CuLCrV}$-recovered plants were inoculated with $\mathrm{CMV}$, symptoms of severe crumpling, curling, yellow spotting, and chlorosis developed in newly emerged leaves by 10 dpi (Fig. 4A; Table 2). Moreover, these symptoms were more severe than those in control plants infected with CMV or CuLCrV alone (Fig. 4A). Furthermore, unlike plants infected with $\mathrm{CuLCrV}$ alone, plants coinfected with $\mathrm{CuLCrV}$ and $\mathrm{CMV}$ did not exhibit recovery for the remainder of the experiment. Levels of CuLCrV DNA in symptomatic leaves from plants co-infected with $\mathrm{CuLCrV}$ and $\mathrm{CMV}$ were much greater than those in equivalent leaves from plants infected with $\mathrm{CuLCrV}$ alone, which were undergoing recovery and were essentially symptomless (i.e., undergoing recovery; Fig. 4B, Table 2). These results suggest that CMV infection disrupted the recovery phenotype, resulting in increased $\mathrm{CuLCrV}$ symptoms and DNA levels.

Accumulation of small RNAs in symptomatic and recovered plants. Small RNAs with nucleotide sequences corresponding to regions of the $\mathrm{CuLCrV}$ genome were detected in leaves from both symptomatic $(10 \mathrm{dpb})$ and recovered $(20 \mathrm{dpb})$ watermelon plants (Fig. 5A). In all cases, levels of the CuLCrV small RNAs were higher in symptomatic tissues compared with those in recovered tissues. Thus, levels of $\mathrm{CuLCrV}$ small RNAs were inversely correlated with the $\mathrm{CuLCrV}$ recovery phenotype, and positively correlated with disease symptoms and viral DNA levels. The CuLCrV small RNAs fell into two sizes: small ( $\approx 24$ to $26 \mathrm{nt}$ ) and large ( $\approx 26$ to $28 \mathrm{nt}$ ). The 'double bands', corresponding to these two sizes of small RNAs, were detected in CuLCrV-infected leaves in multiple independent experiments.

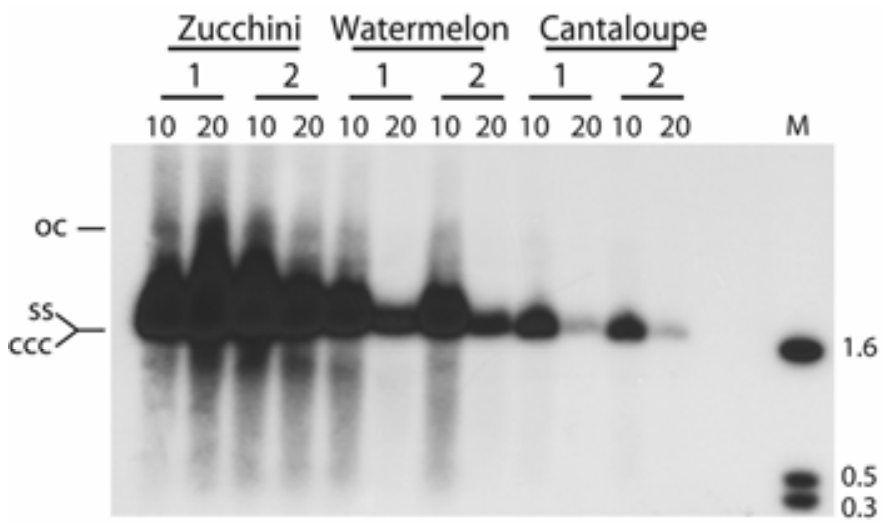

Fig. 2. Levels of Cucurbit leaf crumple virus (CuLCrV) DNA detected in zucchini (cv. Elite), watermelon (cv. Charleston grey), and cantaloupe (cv. Laredo) plants infected with $\mathrm{CuLCrV}$ following particle bombardment inoculation with the cloned DNA-A and DNA-B components. DNA was extracted from newly emerged leaves collected at 10 and 20 days post-bombardment (dpb), and analyzed by DNA gel blot hybridization with a CuLCrV DNA-A and DNA-B probe. The numbers 1 to 2 represent individual plants, and 10 and 20 represent 10 and $20 \mathrm{dpb}$, respectively; oc, ss, and ccc represent open circular, single-stranded and covalently closed circular forms of viral DNA, respectively; and $\mathrm{M}$ indicates the size marker (kilobase pairs). 
Detection of CuLCrV small RNAs in phloem exudate. Small RNAs corresponding to the CuLCrV genome were also detected in RNA samples prepared from phloem exudates collected from CuLCrV-infected pumpkin (cv. Big Max; $30 \mathrm{dpb}$ ) plants, and not in equivalent extracts prepared from phloem exudate from uninfected plants (Fig. 5B). Similar results were obtained with phloem sap collected from $\mathrm{CuLCrV}$-infected pumpkin plants at other timepoints after inoculation (i.e., up to $60 \mathrm{dpb}$; data not shown). The CuLCrV small RNAs detected in the phloem fell into the same two size groups identified in infected leaves: small ( $\approx 24$ to $26 \mathrm{nt}$ ) and large ( $\approx 26$ to $28 \mathrm{nt}$ ). These 'double bands' were detected in phloem exudate from CuLCrV-infected plants in multiple independent experiments.

Methylation of the CuLCrV genome. In assays for methylation of the $\mathrm{CuLCrV}$ genome, control experiments revealed no evidence for inhibitors of restriction enzyme activity in DNA extracts from watermelon or zucchini leaves (i.e., pCuLCrVA 1.5 added to DNA extracts was digested to completion by HpaII or MspI; data not shown). In assays with total genomic DNA extracted from $\mathrm{CuLCrV}$-infected zucchini plants, viral DNA was digested to completion by HpaII (methylation-sensitive) and MspI (methylation-insensitive) at 10, 20, and $30 \mathrm{dpi}$, based upon the disappearance of the undigested supercoiled form and the detection of the expected size restriction fragments (Fig. 6A, B, and C). These results are consistent with the viral DNA in zucchini not being methylated at these sites. In contrast, in equivalent assays performed with total genomic DNA extracted from CuLCrVinfected watermelon, viral DNA was digested to completion by $M s p$ I, whereas a significant portion of supercoiled viral DNA was not digested with HpaII at 10 and 20 dpi (Fig. 6B and C). This indicates that the viral DNA in watermelon was methylated. By 30 dpi, when watermelon leaves had undergone full recovery, viral DNA was barely detectable (Fig. 6B and C).

Treatment of CuLCrV-infected $C$. pepo with pHANNIBAL: Cu-agro. To determine if recovery from $\mathrm{CuLCrV}$ infection could be induced in zucchini, a host that does not show a strong recovery response, the pHANNIBAL system was used to generate a dsRNA corresponding to the viral CR, a region of the genome containing the origin of replication and promoters of viralcomplimentary-sense genes. When CuLCrV-infected zucchini (cv. Elite) plants $(10 \mathrm{dpb})$ were agroinoculated with this construct (pHANNIBAL:Cu-agro), symptoms became noticeably attenuated $\approx 7$ days after the initial treatment, and remained attenuated for the duration of the experiment (a total of three inoculations over a 3 week period) (Fig. 7A and B). Continued weekly agroinoculation with pHANNIBAL:Cu-agro (beyond $24 \mathrm{dpb}$ ) maintained the attenuation of $\mathrm{CuLCrV}$ symptoms. In contrast, symptoms in equivalent $\mathrm{CuLCrV}$-infected zucchini plants, agroinoculated with an 'empty' pHANNIBAL vector, remained relatively severe over the duration of the experiment (Fig. 7C). Viral DNA levels were positively correlated with symptoms; i.e., levels in leaves of $\mathrm{CuLCrV}$-infected plants 7 and 14 days following agro- inoculation with pHANNIBAL:Cu-agro were reduced compared with those in plants agroinoculated with the empty vector control (Fig. 7D). These results were observed in three independent experiments and indicate that the $\mathrm{CuLCrV}$ recovery phenotype can be induced in zucchini.

\section{DISCUSSION}

In this study, we investigated the nature of a recovery phenotype in cucurbits from infection by the bipartite begomovirus, CuLCrV. Recovery from begomovirus infection has been previously reported in several virus-host combinations $(9,11,13)$. However, this is the first reported example of recovery varying among species within a plant family. Thus, a strong and reproducible recovery from $\mathrm{CuLCrV}$ infection occurred in cantaloupe and watermelon plants, but not in zucchini or pumpkin plants. In general, recovery from geminivirus infection seems to be an unusual occurrence (41), as these viruses typically cause severe disease phenotypes in susceptible hosts. This may be due to the underlying (gene silencing) mechanism(s) being more effective against RNA viruses, or the capacity of geminiviruses to avoid or interfere with these host defense mechanisms. The latter situation may be especially true in cases where a begomovirus has become well-adapted to a given host species. Alternatively, the lack of

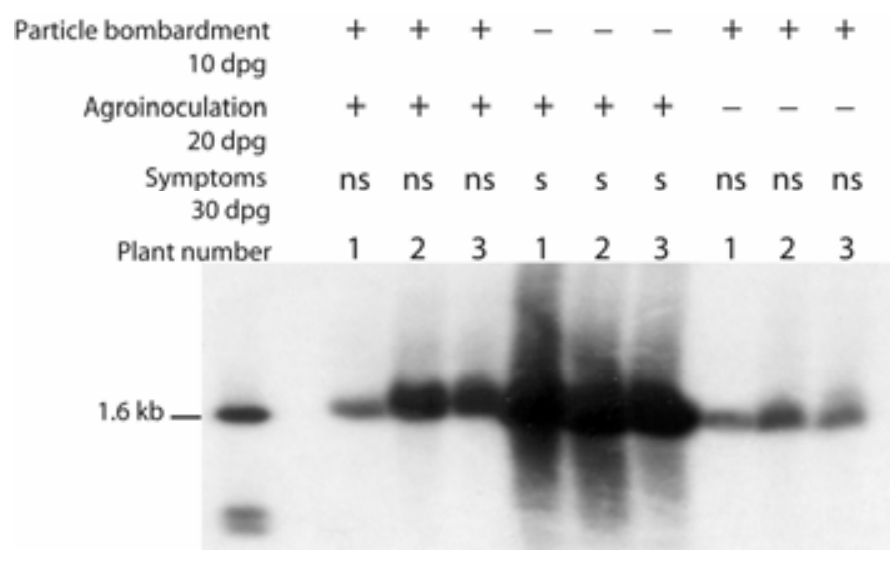

Fig. 3. Disease symptoms and levels of Cucurbit leaf crumple virus (CuLCrV) DNA detected in watermelon (cv. Charleston grey) plants inoculated once or inoculated and re-inoculated with CuLCrV. Treatments are as follows: (i) seedlings inoculated with cloned DNA-A and DNA-B components of CuLCrV by particle bombardment at 10 days post-germination (dpg) and reinoculated by agroinoculation at $20 \mathrm{dpg}$ (left three lanes); (ii) plants agroinoculated with CuLCrV at $20 \mathrm{dpg}$ (middle three lanes), and (iii) seedlings inoculated by particle bombardment at $10 \mathrm{dpg}$ (right three lanes). Symptoms were recorded at $30 \mathrm{dpg}$ and rated as: NS = no obvious symptoms or, $\mathrm{S}=$ symptoms, including stunted growth and leaf curling and crumpling. DNA was extracted from newly emerged leaves at $40 \mathrm{dpg}$ and analyzed for viral DNA levels by DNA gel blot hybridization with a CuLCrV DNA-A and DNA-B probe. The numbers 1 to 3 represent individual plants.

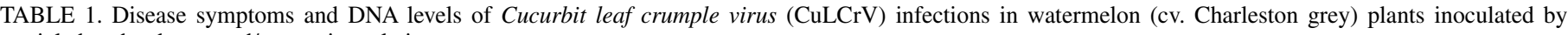
particle bombardment and/or agroinoculation ${ }^{\text {a }}$

\begin{tabular}{|c|c|c|c|c|c|c|}
\hline \multirow[b]{2}{*}{ dpg } & \multicolumn{2}{|c|}{ Inoculated at $10 \mathrm{dpg}$} & \multicolumn{2}{|c|}{ Inoculated at $30 \mathrm{dpg}$} & \multicolumn{2}{|c|}{ Inoculated at 10 and $30 \mathrm{dpg}$} \\
\hline & CuLCrV DNA level $^{\mathrm{b}}$ & Symptom severity ${ }^{\mathrm{c}}$ & CuLCrV DNA level & Symptom severity & CuLCrV DNA level & Symptom severity \\
\hline 10 & - & Absent & - & Absent & - & Absent \\
\hline 20 & High & Severe & - & Absent & High & Severe \\
\hline 30 & Moderate & Moderate & - & Absent & Moderate & Moderate \\
\hline 40 & Low & Mild/absent & High & Severe & Low & Mild/absent \\
\hline 50 & Low & Mild/absent & Moderate & Moderate & Low & Mild/absent \\
\hline
\end{tabular}

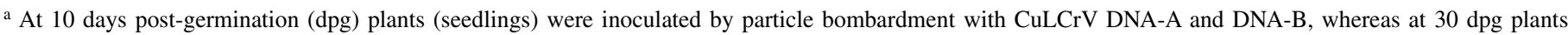
were agroinoculated with CuLCrV. Results of three independent experiments with a minimum of three plants per experiment/treatment.

b Viral DNA levels were determined by DNA gel blot hybridization with a CuLCrV DNA-A and DNA-B probe.

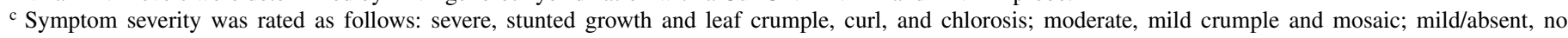
obvious symptoms. 
reports on recovery from geminivirus infection may reflect the virus-host combinations that have been examined to date. For example, infections of hosts to which begomoviruses are not welladapted are characterized by mild and asymptomatic phenotypes and low viral titers (27). This phenotype may reflect bona fide recovery, the effectiveness of ongoing host defense responses, or an incompatibility of viral proteins with host factors. As $\mathrm{CuLCrV}$ is a newly emergent begomovirus, the differences in the recovery phenotype in various cucurbit hosts may well reflect an ongoing host adaptation process.

Viral DNA levels (i.e., viral titer) were significantly reduced in tissues undergoing recovery compared with levels in symptomatic non-recovered tissues. Because we have found no evidence for

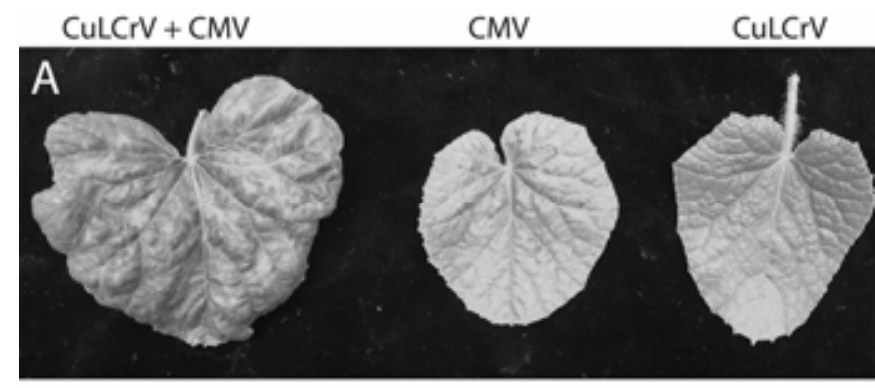

B

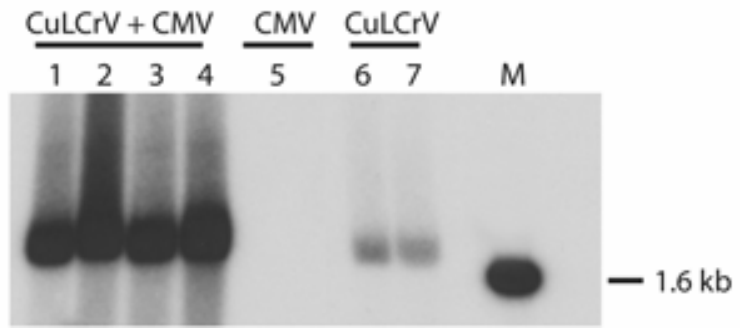

Fig. 4. Disease symptoms and levels of Cucurbit leaf crumple virus (CuLCrV) DNA detected in cantaloupe (cv. Laredo) plants undergoing recovery from $\mathrm{CuLCrV}$ infection and infected with Cucumber mosaic virus (CMV). Treatments are as follows: (i) cantaloupe plants (cv. Laredo) infected with CuLCrV by particle bombardment with the cloned multimeric CuLCrV DNA-A and DNA-B components at 10 days post-germination (dpg), allowed to undergo recovery, and then sap-inoculated with CMV at $30 \mathrm{dpg}$; (ii) uninfected cantaloupe plants sap-inoculated with CMV at $30 \mathrm{dpg}$, and (iii) cantaloupe plants infected with $\mathrm{CuLCrV}$ by particle bombardment at $10 \mathrm{dpg}$. A, Cantaloupe leaves (true leaf number 24 taken at $40 \mathrm{dpg}$ ) from plants inoculated with: CuLCrV and CMV (left), CMV (middle) or CuLCrV (right). B, Levels of $\mathrm{CuLCrV}$ DNA in individual cantaloupe plants infected with $\mathrm{CuLCrV}$ and CMV (lanes 1 to 4), CMV (lane 5), or CuLCrV (lanes 6 and 7). DNA was extracted from newly emerged leaf tissue at $40 \mathrm{dpg}$ and analyzed for viral DNA levels by DNA gel blot hybridization with a CuLCrV DNA-A and DNAB probe. developmental-type resistance (i.e., resistance in older tissues) to $\mathrm{CuLCrV}$ infection in cucurbits, it is reasonable to conclude that the reduced viral titer in recovered tissues reflects an ongoing host defense mechanism. Recovery phenotypes characterized in other virus-host interactions have been associated with VIGS, an active and adaptive plant defense mechanism $(2,37,43)$. Thus, in order to determine whether VIGS was the underlying mechanism of recovery from $\mathrm{CuLCrV}$ infection, we performed a series of reinoculation studies with $\mathrm{CuLCrV}$-recovered plants. The finding that recovered plants were highly resistant to reinfection by $\mathrm{CuLCrV}$ is consistent with the development of an antiviral response. Furthermore, the susceptibility of CuLCrV-recovered plants to infection by CMV revealed the specificity of the recovery response. $\mathrm{CMV}$ infection of CuLCrV-recovered plants also resulted in the reversal or suppression of the recovery phenotype, such that there

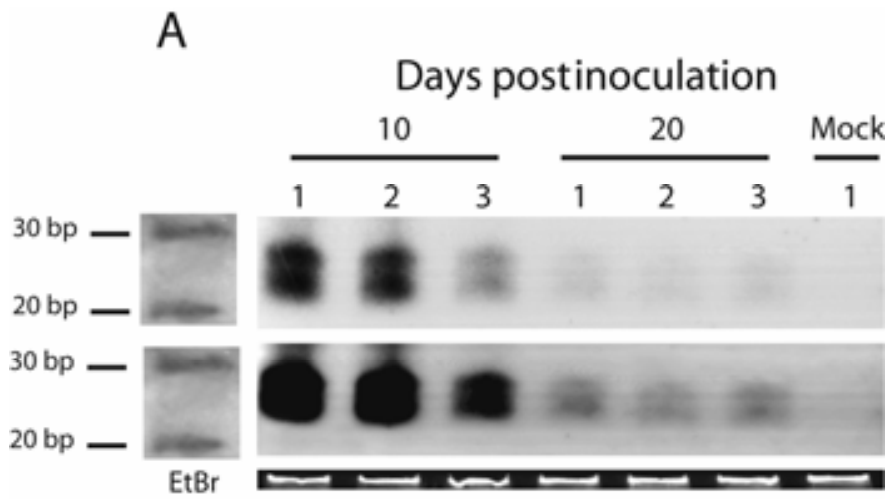

B

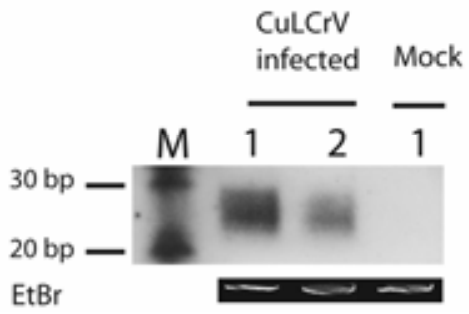

Fig. 5. Detection of small RNAs homologous to Cucurbit leaf crumple virus $(\mathrm{CuLCrV})$ in infected cucurbit plants. A, CuLCrV small RNAs detected in newly emerged leaves of watermelon (cv. Charleston grey) plants infected with $\mathrm{CuLCrV}$ at 10 or 20 days following particle bombardment (dpb) with the cloned multimeric CuLCrV DNA-A and DNA-B clones. Short (upper figure) and long (lower figure) exposures are shown, and a different exposure was used for the markers (20 and $30 \mathrm{bp}$ ). B, CuLCrV small RNAs detected in phloem exudate prepared from CuLCrV-infected pumpkin (cv. Big Max) plants at $30 \mathrm{dpb}$. Phloem exudate from an uninfected pumpkin plant was used as a control. Ethidium bromide staining of RNA in the polyacrylamide gel was used as a loading control.

TABLE 2. Disease symptoms and DNA levels associated with Cucurbit leaf crumple virus (CuLCrV) infections in cantaloupe plants (cv. Laredo) inoculated with CuLCrV, Cucumber mosaic virus (CMV), or CuLCrV and CMV ${ }^{\mathrm{a}}$

\begin{tabular}{|c|c|c|c|c|c|c|}
\hline \multirow[b]{2}{*}{ dpg } & \multicolumn{2}{|c|}{ Inoculated with $\mathrm{CuLCrV}$ at $10 \mathrm{dpg}$} & \multicolumn{2}{|c|}{ Inoculated with CuLCrV at $10 \mathrm{dpg}+\mathrm{CMV}$ at $30 \mathrm{dpg}$} & \multicolumn{2}{|c|}{ Inoculated with CMV at $30 \mathrm{dpg}$} \\
\hline & CuLCrV DNA level $^{\mathrm{b}}$ & Symptom severity ${ }^{\mathrm{c}}$ & CuLCrV DNA level & Symptom severity & CuLCrV DNA level & Symptom severity \\
\hline 10 & - & Absent & - & Absent & - & - \\
\hline 40 & Low & Mild/absent & High & Severe & - & Moderate \\
\hline 50 & Low & Mild/absent & High & Severe & - & Moderate \\
\hline
\end{tabular}

${ }^{a}$ At 10 days post-germination (dpg) plants (seedlings) were inoculated with CuLCrV DNA-A and DNA-B by particle bombardment, whereas at 30 dpg plants were inoculated with CMV by sap-inoculation. Results of three independent experiments with a minimum of three plants per experiment/treatment.

b Viral DNA levels were determined by DNA gel blot hybridization with a CuLCrV DNA-A and DNA-B probe.

${ }^{c}$ Typical symptoms of CuLCrV infection included stunted growth and leaf crumple, curl, and yellowing; whereas typical symptoms of CMV infection included mottle, yellow spots, and mild leaf crumple without recovery. Plants infected with both viruses developed severe stunted growth, and leaf crumple, and yellow mottle without recovery. 
was an increase in $\mathrm{CuLCrV}$ titer and the development of a synergistic severe symptom phenotype. This suggests that CMV provides a factor involved in the suppression of the recovery process, possibly the CMV $2 \mathrm{~b}$ protein, a known suppressor of gene silencing $(6,12,29,49)$.

Given the adaptive nature of the $\mathrm{CuLCrV}$ recovery phenotype and the suppression of the response by coinfection with a virus that expresses a strong suppressor of gene silencing, we reasoned that VIGS was involved with the recovery phenotype. Thus, we looked for the classic hallmarks of gene silencing: small RNAs corresponding to the target of silencing. Indeed, we detected $\mathrm{CuLCrV}$ small RNAs in both recovered and nonrecovered plant tissues, as well as from the phloem exudate from CuLCrVinfected pumpkin plants. These findings are fully consistent with a role for gene silencing in the CuLCrV-recovery phenotype.

Interestingly, the abundance of $\mathrm{CuLCrV}$-homologous small RNA was negatively correlated with recovery and positively correlated with viral titer. This is in contrast with results of a previous study indicating that the abundance of small RNAs was
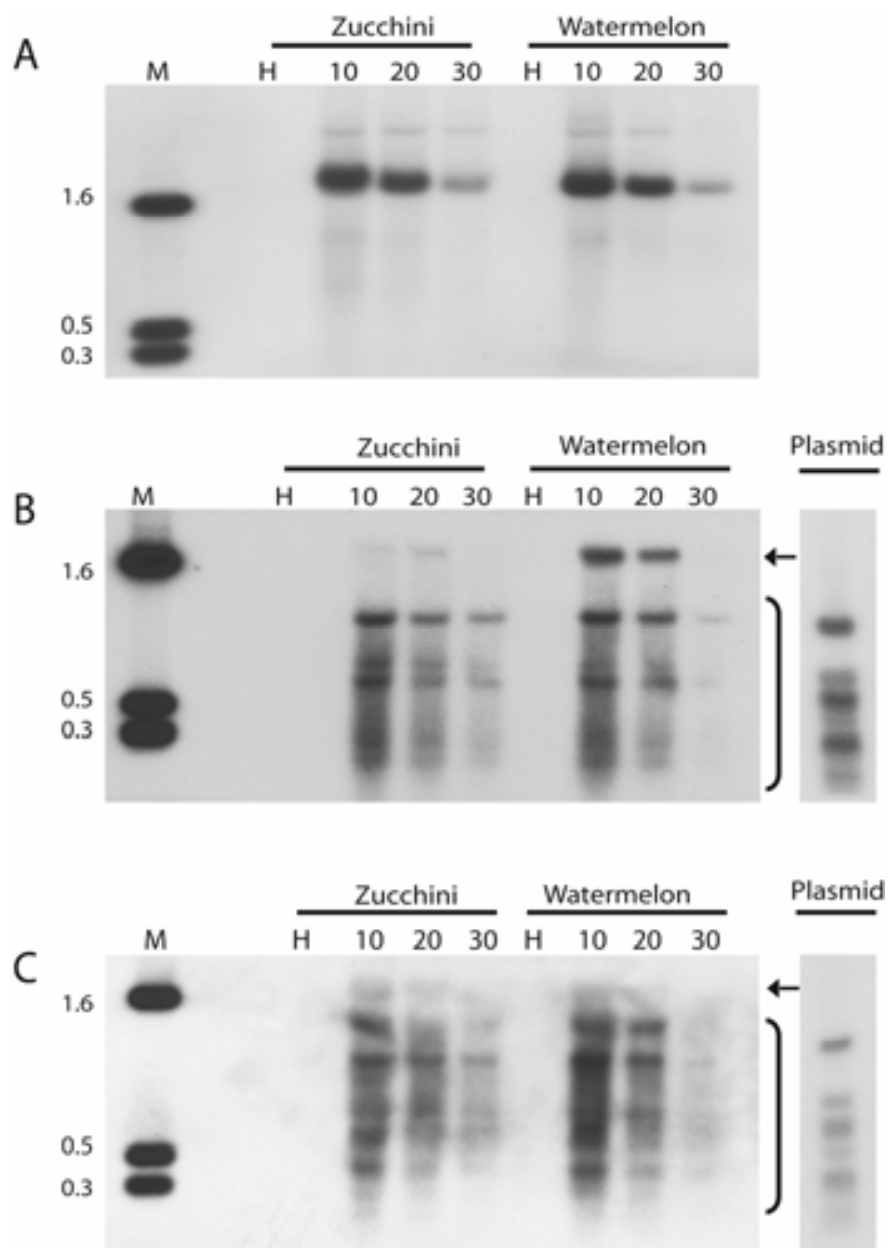

Fig. 6. Methylation of the Cucurbit leaf crumple virus (CuLCrV) genomic DNA in cucurbits undergoing recovery. Watermelon (cv. Charleston grey, undergoes recovery) and zucchini (cv. Elite, undergoes limited recovery) plants were infected with $\mathrm{CuLCrV}$ by agroinoculation. Total genomic DNA was extracted from newly emerged leaves at 10,20, and 30 days postinoculation (dpi), digested with HpaII or MspI (methylation-sensitive or insensitive isoschizomers) and analyzed by Southern blot hybridization with a ${ }^{32} \mathrm{P}$-labeled CuLCrV DNA-A probe. A, Undigested total genomic DNA, B, total genomic DNA digested with HpaII (methylation sensitive) and then treated with mung bean nuclease, and $\mathbf{C}$, total genomic DNA digested with $M s p \mathrm{I}$ (methylation insensitive) and then treated with mung bean nuclease. Plasmid represents the cloned CuLCrV DNA-A digested with B, HpaI and C, MspI. Arrows indicate the undigested covalently closed circular form of CuLCrV DNA-A and brackets show CuLCrV DNA-A restriction fragments $(\approx 1,000,600,400$, and $300 \mathrm{bp})$. negatively correlated with viral titer in plants undergoing recovery from begomovirus infection (13). An explanation for this discrepancy may come from an examination of the different virushost combinations used in these experiments. Chellappan et al. (13) investigated the interaction between several cassava mosaic viruses, including ACMV, and cassava (the natural host) and $N$. benthamiana, an experimental host that is not infected by these viruses in nature. The most striking evidence of recovery and elevated levels of siRNA in recovered tissues was in $N$. benthamiana infected with ACMV, which may be due to the virus being less well adapted to this host, resulting in a stronger recovery response. In the present study, we examined the $\mathrm{CuLCrV}$ recovery phenotype in natural hosts in which the virus is presumably better adapted (and able to combat host defense responses). Our results are more consistent with those of CarrilloTripp et al. (11) who examined recovery in pepper from infection with PepGMV, and found abundant viral small RNAs in tissues of symptomatic and recovered plants.

According to our understanding of RNA silencing $(37,42)$, small RNAs produced during the silencing of an invasive genetic element, such as a virus, are degradation products of virally derived RNAs. In the case of begomoviruses, this is presumably one or more viral mRNAs. Therefore, the abundance of small RNA would presumably relate to the relative abundance of the full-length or partial-length template. The substantial decrease in $\mathrm{CuLCrV}$ titer during recovery may reflect a decrease in viralassociated RNAs via RISC-mediated RNA degradation. This would, in turn, reduce levels of viral proteins, leading to reduced viral replication. As the abundance of the viral-derived RNAs decreases in recovered tissues, so would the abundance of the CuLCrV-corresponding small RNA. This relationship could be
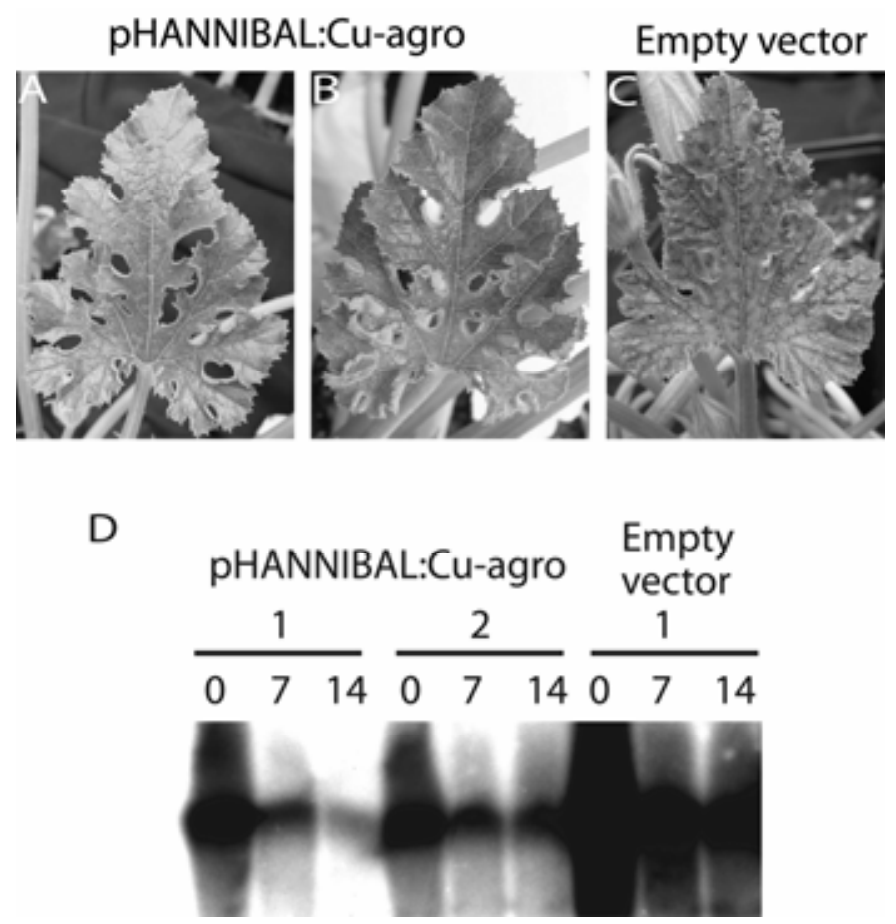

Fig. 7. Agroinoculation of Cucurbit leaf crumple virus (CuLCrV)-infected zucchini plants with an inverted repeat construct corresponding to the common region of the CuLCrV genome (pHANNIBAL:Cu-agro). A and B, leaves of CuLCrV-infected zucchini (cv. Elite) plants agroinoculated three times, at weekly intervals, with pHANNIBAL:Cu-agro and $\mathbf{C}$, leaves from an equivalent $\mathrm{CuLCrV}$-infected plant agroinoculated with the empty vector control. Photographs were taken 21 days after the initial inoculation with pHANNIBAL:Cu-agro. D, Levels of CuLCrV DNA detected in pHANNIBAL: Cu-agro- or empty vector control-treated plants. DNA was extracted from newly emerged leaf tissue at 0,7 , and 14 days after the initial inoculation of pHANNIBAL:Cu-agro. 
thought of as a 'dynamic equilibrium' or feedback loop that protects the plant from extensive viral infection, but also does not completely eliminate the pathogen. Consistent with this hypothesis is the observation that CuLCrV was still detectable in recovered tissues, both by PCR and by reemergence following CMV infection. The severe symptoms and high viral titer observed early in the infection process reflect rapid viral replication and spread, before silencing develops. Once established however, this adaptive response develops quickly, as demonstrated by the rapid attenuation of symptoms and our inability to reinfect recovered plants with $\mathrm{CuLCrV}$. Infection with $\mathrm{CMV}$, which expresses a known suppressor of gene silencing, presumably disrupts this equilibrium, by suppressing the silencing pathway involved in $\mathrm{CuLCrV}$ recovery, thereby allowing subsequent redevelopment of symptoms. This result is also consistent with reports indicating that DICER-like proteins can function to mediate gene silencing of both RNA and DNA viruses (5).

The abundance of CuLCrV-corresponding small RNA in the phloem of infected $C$. maxima plants provides an explanation of how a silencing signal might move to sink tissues to initiate the recovery process. The rate at which these putative signaling molecules move in the phloem relative to the virus, is of paramount importance in terms of establishing an effective silencing-based defense response. Thus, in cucurbits with determinant growth such as zucchini, the signal may not trigger silencing soon enough, in terms of viral spread and colonization, to generate a strong recovery response. In cucurbits with more indeterminate growth, such as cantaloupe and watermelon, the putative signal may move faster than the virus, thereby allowing for better establishment of silencing prior to viral infection. An alternative hypothesis is that the virus-homologous small $\mathrm{RNA}(\mathrm{s})$ are acting in quite the opposite manner, by acting as miRNAs and triggering the silencing of key defense-related genes in nonrecovering hosts such as zucchini, and thereby priming new tissues for infection $(18,44)$.

The CuLCrV-homologous small RNAs identified in infected watermelon and pumpkin plants fell into two distinct size groups, $\approx 24$ to 26 and $\approx 26$ to $28 \mathrm{nt}$. This bimodal distribution pattern is consistent with the results of others $(1,11,13,21)$, although the sizes detected in the present study are slightly larger. However, it has been reported that small RNAs, up to $27 \mathrm{nt}$, can be found in uninfected C. maxima plants (47). Thus, the sizes of the small RNAs in cucurbits may well reflect the host-specific properties of the DICER complex.

To determine if gene silencing mechanisms are active against CuLCrV DNA in recovered tissues, we investigated the level of DNA methylation of the $\mathrm{CuLCrV}$ genome. Our results suggest that DNA methylation was more prevalent in a host undergoing strong recovery (watermelon) compared with a host undergoing limited recovery (zucchini). Thus, methylation of the viral genome may contribute to the attenuation of viral symptoms through reduced gene expression or replication. This result is consistent with an RNA-directed DNA methylation mechanism $(28,30$, $35,45)$, and the perceived function of DNA methylation in plants, which is to attenuate gene expression $(3,33,38)$.

Finally, the recovery phenotype was induced in zucchini through the introduction of a genetic construct designed to trigger $\mathrm{CuLCrV}$ silencing. This construct was derived from the $\mathrm{CuLCrV}$ $\mathrm{CR}$, the $194 \mathrm{bp}$ region shared between the CuLCrV DNA-A and DNA-B components (20). As the CR contains the viral origin of replication and promoters for viral and complementary-sense genes, it was chosen as a target likely to affect the fitness of the virus. Indeed, agroinoculation of this construct resulted in the attenuation of $\mathrm{CuLCrV}$ symptoms and a reduction in viral titer in $\mathrm{CuLCrV}$-infected zucchini. However, unlike natural recovery from $\mathrm{CuLCrV}$, the attenuation of symptoms in zucchini required the continued agroinoculation of the silencing construct; we were unable to trigger a bona fide self-sustaining recovery phenotype (data not shown). Nonetheless, this result provides another line of evidence that $\mathrm{CuLCrV}$ recovery is mediated by gene silencing, but it also raises the question of why natural recovery does not occur in Cucurbita spp., as the required cellular components are present and functional in zucchini.

In this work we have investigated and characterized host recovery from infection by $\mathrm{CuLCrV}$, a bipartite begomovirus. Recovery is host species-specific and is characterized by a significant and persistent decrease in both viral titer and symptom severity. Recovery is associated with many of the hallmarks of gene silencing, including the presence of small RNAs and disruption by a virus known to interfere with RNA silencing. From a practical standpoint, it is encouraging that gene silencing can act against geminiviruses to induce persistent recovery under natural conditions, and supports the further use of gene silencing approaches for generating geminivirus-resistant crops. One potential approach would be the transformation of a geminivirus-derived inverted repeat sequence into a susceptible crop species, thereby allowing for continuous virus protection.

\section{ACKNOWLEDGMENTS}

Financial support was provided by the California Melon Board. We thank S.-W. Ding, B. Falk, and W. J. Lucas for helpful suggestions and discussions.

\section{LITERATURE CITED}

1. Akbergenov, R., Si-Ammour, A., Blevins, T., Amin, I., Kutter, C., Vanderschuren, H., Zhang, P., Gruissem, W., Meins, F., Jr., Hohn, T., and Pooggin, M. M. 2006. Molecular characterization of geminivirus-derived small RNAs in different plant species. Nucleic Acids Res. 34:462-471.

2. Baulcombe, D. 2004. RNA silencing in plants. Nature 431:356-363.

3. Bender, J. 2004. DNA methylation and epigenetics. Annu. Rev. Plant Biol. 55:41-68.

4. Bernstein, E., Kim, S. Y., Carmell, M. A., Murchison, E. P., Alcorn, H., Li, M. Z., Mills, A. A., Elledge, S. J., Anderson, K. V., and Hannon, G. J. 2003. Dicer is essential for mouse development. Nat. Genet. 35:215-217.

5. Blevins, T., Rajeswaran, R., Shivaprasad, P. V., Beknazariants, D., SiAmmour, A., Park, H. S., Vazquez, F., Robertson, D., Meins, F., Jr., Hohn, T., and Pooggin, M. M. 2006. Four plant Dicers mediate viral small RNA biogenesis and DNA virus induced silencing. Nucleic Acids Res. 34:6233-6246.

6. Brigneti, G., Voinnet, O., Li, W. X., Ji, L. H., Ding, S. W., and Baulcombe, D. C. 1998. Viral pathogenicity determinants are suppressors of transgene silencing in Nicotiana benthamiana. EMBO J. 17:67396746.

7. Brough, C. L., Gardiner, W. E., Inamdar, N. M., Zhang, X. Y., Ehrlich, M., and Bisaro, D. M. 1992. DNA methylation inhibits propagation of DNA in transfected protoplasts. Plant Mol. Biol. 18:703-712.

8. Brown, J. K., Idris, A. M., Alteri, C., and Stenger, D. C. 2002. Emergence of a new cucurbit-infecting begomovirus species capable of forming viable reassortants with related viruses in the Squash leaf curl virus cluster. Phytopathology 92:734-742.

9. Brown, J. K., Idris, A. M., Ostrow, K. M., Goldberg, N., French, R., and Stenger, D. C. 2005. Genetic and phenotypic variation of the Pepper golden mosaic virus complex. Phytopathology 95:1217-1224.

10. Carmell, M. A., and Hannon, G. J. 2004. RNase III enzymes and the initiation of gene silencing. Nat. Struct. Mol. Biol. 11:214-218.

11. Carrillo-Tripp, J., Lozoya-Gloria, E., and Rivera-Bustamante, R. F. 2007. Symptom remission and specific resistance of pepper plants after infection by Pepper golden mosaic virus. Phytopathology 97:51-59.

12. Chapman, E. J., Prokhnevsky, A. I., Gopinath, K., Dolja, V. V., and Carrington, J. C. 2004. Viral RNA silencing suppressors inhibit the microRNA pathway at an intermediate step. Genes Dev. 18:1179-1186.

13. Chellappan, P., Masona, M. V., Vanitharani, R., Taylor, N. J., and Fauquet, C. M. 2004. Broad spectrum resistance to ssDNA viruses associated with transgene-induced gene silencing in cassava. Plant Mol. Biol. 56:601-611.

14. Covey, S. N., Al-Kaff, N. S., Langara, A., and Turner, D. S. 1997. Plants combat infection by gene silencing. Nature 385:781-782.

15. Dellaporta, S. L., Wood, J., and Hicks, J. B. 1983. A plant DNA minipreparation: Version II. Plant Mol. Biol. Rep. 1:19-21.

16. Ermak, G., Paszkowski, U., Wohlmuth, M., Scheid, O. M., and Paszkowski, J. 1993. Cytosine methylation inhibits replication of African cassava mosaic virus by 2 distinct mechanisms. Nucleic Acids Res. $21: 3445-3450$ 
17. Gleave, A. P. 1992. A versatile binary vector system with a T-DNA organizational-structure conducive to efficient integration of cloned DNA into the plant genome. Plant Mol. Biol. 20:1203-1207.

18. Gupta, A., Gartner, J. J., Sethupathy, P., Hatzigeorgiou, A. G., and Fraser, N. W. 2006. Anti-apoptotic function of a microRNA encoded by the HSV1 latency-associated transcript. Nature 442:82-85.

19. Guzman, P., Sudarshana, M. R., Seo, Y. S., and Rojas, M., Natwick, E., Turini, Mayberry, K., and Gilbertson, R. L. 2000. A new bipartite geminivirus (Begomovirus) causing leaf curl and crumpling in cucurbits in the Imperial Valley of California. Plant Dis. 84:488.

20. Hagen, C., Rojas, M. R., Sudarshana, M. R., Xoconostle-Cazares, B., Natwick, E., Turini, T. A., and Gilbertson, R. L. 2008. Biology and molecular characterization of Cucurbit leaf crumple virus, an emergent cucurbit-infecting begomovirus in the Imperial Valley of California. Plant Dis. 92:781-793.

21. Hamilton, A., Voinnet, O., Chappell, L., and Baulcombe, D. 2002. Two classes of short interfering RNA in RNA silencing. EMBO J. 21:4671-4679.

22. Hammond, S. M., Boettcher, S., Caudy, A. A., Kobayashi, R., and Hannon, G. J. 2001. Argonaute2, a link between genetic and biochemical analyses of RNAi. Science 293:1146-1150.

23. Hannon, G. J. 2002. RNA interference. Nature 418:244-251.

24. Helliwell, C. A., and Waterhouse, P. M. 2005. Constructs and methods for hairpin RNA-mediated gene silencing in plants. Methods Enzymol. 392:24-35.

25. Hernandez, N. A., Sudarshana, M. R., Guzman, P., and Gilbertson, R. L. 2001. Generation and characterization of infectious clones of Cucurbit leaf crumple virus, a new bipartite geminivirus from the Imperial Valley of California. (Abstr.) Phytopathology 91(suppl.):S35.

26. Hou, Y. M., and Gilbertson, R. L. 1996. Increased pathogenicity in a pseudorecombinant bipartite geminivirus correlates with intermolecular recombination. J. Virol. 70:5430-5436.

27. Hou, Y. M., Paplomatas, E. J., and Gilbertson, R. L. 1998. Host adaptation and replication properties of two bipartite geminiviruses and their pseudorecombinants. Mol. Plant-Microbe Interact. 11:208-217.

28. Jones, P. A. 1999. The DNA methylation paradox. Trends Genet. 15:34-37.

29. Lucy, A. P., Guo, H. S., Li, W. X., and Ding, S. W. 2000. Suppression of post-transcriptional gene silencing by a plant viral protein localized in the nucleus. EMBO J. 19:1672-1680.

30. Mathieu, O., and Bender, J. 2004. RNA-directed DNA methylation. J. Cell Sci. 117:4881-4888.

31. Paplomatas, E. J., Patel, V. P., Hou, Y. M., Noueiry, A. O., and Gilbertson, R. L. 1994. Molecular characterization of a new sap-transmissible bipartite genome geminivirus infecting tomatoes in Mexico. Phytopathology 84:1215-1224.

32. Peragine, A., Yoshikawa, M., Wu, G., Albrecht, H. L., and Poethig, R. S. 2004. SGS3 and SGS2/SDE1/RDR6 are required for juvenile development and the production of trans-acting siRNAs in Arabidopsis. Genes Dev. 18:2368-2379.

33. Pollack, Y., Stein, R., Razin, A., and Cedar, H. 1980. Methylation of foreign DNA sequences in eukaryotic cells. Proc. Natl. Acad. Sci. USA 77:6463-6467.
34. Ratcliff, F., Harrison, B. D., and Baulcombe, D. C. 1997. A similarity between viral defense and gene silencing in plants. Science 276:15581560 .

35. Rodman, M. K., Yadav, N. S., and Artus, N. N. 2002. Progression of geminivirus-induced transgene silencing is associated with transgene methylation. New Phytol. 155:461-468.

36. Sambrook, J., Fritsch, E. F., and Maniatis, T. 1989. Molecular cloning: A laboratory manual. Cold Spring Harbor Laboratory Press, Cold Spring Harbor, NY.

37. Saumet, A., and Lecellier, C. H. 2006. Anti-viral RNA silencing: Do we look like plants? Published online. Retrovirology 3: doi:10.1186/17424690-3-3.

38. Seemanpillai, M., Dry, I., Randles, J., and Rezaian, A. 2003. Transcriptional silencing of geminiviral promoter-driven transgenes following homologous virus infection. Mol. Plant-Microbe Interact. 16:429-438.

39. Seo, Y. S., Rojas, M. R., Lee, J. Y., Lee, S. W., Jeon, J. S., Ronald, P., Lucas, W. J., and Gilbertson, R. L. 2006. A viral resistance gene from common bean functions across plant families and is up-regulated in a non-virus-specific manner. Proc. Natl. Acad. Sci. USA 103:1185611861.

40. Sunkar, R., and Zhu, J. K. 2004. Novel and stress-regulated microRNAs and other small RNAs from Arabidopsis. Plant Cell 16:2001-2019.

41. Vanitharani, R., Chellappan, P., and Fauquet, C. M. 2005. Geminiviruses and RNA silencing. Trends Plant Sci. 10:144-151.

42. Vaucheret, H. 2006. Post-transcriptional small RNA pathways in plants: mechanisms and regulations. Genes Dev. 20:759-771.

43. Voinnet, O. 2001. RNA silencing as a plant immune system against viruses. Trends Genet. 17:449-459.

44. Wang, M. B., Bian, X. Y., Wu, L. M., Liu, L. X., Smith, N. A., Isenegger, D., Wu, R. M., Masuta, C., Vance, V. B., Watson, J. M., Rezaian, A., Dennis, E. S., and Waterhouse, P. M. 2004. On the role of RNA silencing in the pathogenicity and evolution of viroids and viral satellites. Proc. Natl. Acad. Sci. USA 101:3275-3280.

45. Wassenegger, M., Heimes, S., Riedel, L., and Sanger, H. L. 1994. RNA directed de novo methylation of genomic sequences in plants. Cell 76:567-576.

46. Wesley, S. V., Helliwell, C. A., Smith, N. A., Wang, M. B., Rouse, D. T., Liu, Q., Gooding, P. S., Singh, S. P., Abbott, D., Stoutjesdijk, P. A., Robinson, S. P., Gleave, A. P., Green, A. G., and Waterhouse, P. M. 2001. Construct design for efficient, effective and high-throughput gene silencing in plants. Plant J. 27:581-590.

47. Yoo, B. C., Kragler, F., Varkonyi-Gasic, E., Haywood, V., Archer-Evans, S., Lee, Y. M., Lough, T. J., and Lucas, W. J. 2004. A systemic small RNA signaling system in plants. Plant Cell 16:1979-2000.

48. Zamore, P. D. 2002. A surveillance system regulates selective entry of RNA into the shoot apex: Ancient pathways programmed by small RNAs. Science 296:1265-1269.

49. Zhang, X., Yuan, Y. R., Pei, Y., Lin, S. S., Tuschl, T., Patel, J. P., and Chua, N. H. 2006. Cucumber mosaic virus-encoded $2 \mathrm{~b}$ suppressor inhibits Arabidopsis Argonaute1 cleavage activity to counter plant defense. Genes Dev. 20:3255-3268. 